\title{
Physicochemical properties of Cucumis melo var. inodorus (honeydew melon) seed and seed oil
}

\begin{abstract}
Cucumis melo var. inodorus seeds were found to contain $4.5 \%$ moisture, $25.0 \%$ crude fat, $25.0 \%$ crude protein, $23.3 \%$ crude fiber, $2.4 \%$ ash and $19.8 \%$ carbohydrate. The iodine and saponification values, and unsaponifiable matter and free fatty acid contents of freshly extracted honeydew melon seed oil were $153.4 \mathrm{~g} \mathrm{I} / 100 \mathrm{~g}$ oil, $210.2 \mathrm{mg} \mathrm{KOH} / \mathrm{g}$ oil, 0.9 and $2.5 \%$, respectively. The oil had a color index of $1.6 \mathrm{Y}+0.4 \mathrm{R}$, and had 10 fatty acids, of which $86.1 \%$ were unsaturated. Linoleic acid predominated with $69.0 \%$ followed by oleic acid $(16.8 \%)$ and palmitic acid (8.4\%). LLL (24.9\%), OLL (21.5\%), PLL (15.9\%) and POL (12.4\%) (where L, O, P and S denote linoleic, oleic, palmitic and stearic acids, respectively) were the major triacylglycerols present. The melting and crystallization temperatures were -5.12 and $-59.01 \mathrm{C}$, respectively. Electronic nose analysis showed the presence of more volatile compounds compared to refined sunflower oil, an oil rich also in linoleic acid.
\end{abstract}

